\title{
SOLID PARTICLE EROSION RESISTANCE OF AI ALLOY AND AI ALLOY-FLY ASH COMPOSITE SUBJECTED TO EQUAL-CHANNEL ANGULAR PRESSING
}

\author{
Merima Muslić, ${ }^{1, *}$, Vera Rede ${ }^{2}$,Vesna Maksimovic ${ }^{3}$ \\ ${ }^{1}$ Ltd. E-PRO for design, engineering and technical consulting, Bihać, \\ Bosnia and Herzegovina, \\ ${ }^{2}$ Faculty of Mechanical Engineering and Naval Architecture, University of Zagreb, \\ Zagreb, Croatia \\ ${ }^{3}$ Vinča Institute of Nuclear Sciences - National Institute of the Republic of Serbia, \\ University of Belgrade, Mike Petrovića Alasa 12-14, 11001 Belgrade, Serbia
}

Received 08.03.2021

Accepted 18.03.2021

\begin{abstract}
This paper describes the influence of deformation by equal-channel angular pressing (ECAP) on the solid particle erosion resistance of the AlSi7Mg0.3 alloy and $\mathrm{AlSi} 7 \mathrm{Mg} 0.3$ based composite material reinforced with the addition of $4 \%$ of fly ash (FA) particles. Both, alloy and composite samples were produced using the compo-casting method. The samples have been subjected to ECAP in multiple passes with the rotation of samples around the vertical axis for the angle of $90^{\circ}$ after each pass. Particles of silicon carbide $(\mathrm{SiC})$ have been used as erodent while their impact angle was varied $\left(30^{\circ}\right.$ and $90^{\circ}$ ). Observed samples of AlSi7Mg0.3 alloy generally showed higher wear resistance at $90^{\circ}$ angle where material fatigue predominates, than at a $30^{\circ}$ angle where abrasion-related phenomena predominate. On the other hand, AlSi7Mg0.3 based composite material exhibited erosion wear at $30^{\circ}$ angle less than at $90^{\circ}$ angle after one ECAP pass. Evaluation of the erosion resistance has been made based on mass and volume loss. After two passes of ECAP, the matrix structure of the AlSi7Mg0.3 based composite material, as well as that of the AlSi7Mg0.3 alloy was improved from the aspect of erosion resistance.
\end{abstract}

Keywords: Erosion resistance; Al alloy; Al matrix composite; Fly ash; Equalchannel angular pressing.

\section{Introduction}

In the production of composites based on aluminum and its alloys, fly ash (FA) can be used as reinforcement. The fly ash is generated as a side-product of coal

${ }^{*}$ Corresponding author: Merima Muslić,dmuslic@bih.net.ba 
combustion in thermal power plants and collected in flue gas filters. FA is a lower density material presenting a non-homogeneous mixture of metallic oxides in the form of filled and hollow spherical particles with a diameter between 1 and 120 microns. FA composition depends mostly on the type and origin of the coal burned in the thermal power plant and the mode of operation of the thermal power plant. About 370 million tons of FA are produced annually globally [1] and its disposal represents a serious ecological problem [1-4]. Previous studies [5-10] have shown that by using FA as a reinforcement in the matrix based on aluminum and its alloys, a composite with lower density with properties same or better than the base material can be obtained. Properties of such composite materials can be further improved by applying a plastic deformation treatment process [11-13]. One of the insufficiently researched processes is equal-channel angular pressing - ECAP. In this process, the material is pressed through an L-shaped angular channel where it is exposed to intensive plastic deformation resulting in changes in the material structure. The research shows an improvement to the properties of the pressed material: increase in strength, hardness and wear resistance $[11,12]$.

Erosion can be defined as the wear of the material due to the impact of solid particles on its surface. This phenomenon represents serious engineering problems, for example in the pipelines, hydraulic and pneumatic systems, aircraft components, pneumatic transport, and similar. Many influencing factors in the process of solid particle erosion have been recognized, such as size, shape, and hardness of the solid particles, their velocity and impact angle, as well as properties of the tested material. Many studies have shown that alternation in the impact angle changes the dominant wear mechanism. At smaller impact angles $\left(30^{\circ}\right)$ abrasion appears as the dominant wear mechanism, while at higher impact angles $\left(90^{\circ}\right)$ the dominant mechanism is surface fatigue. Different behaviors have been noted at ductile and brittle materials. Ductile materials have better resistance at higher impact angles while this is the opposite at brittle materials [14-21].

Due to all given above, the analysis of solid particle erosion is an important subject of research in the development of new composite materials. This paper describes the methods and results of solid particle erosion resistance of the composite based on $\mathrm{AlSi} 7 \mathrm{Mg} 0.3$ and $4 \%$ of FA and compares them to the AlSi7Mg0.3 alloy. To improve the properties of the material ECAP of individual AlSi7Mg0.3 alloy and AlSi7Mg0.3 based composite samples has been performed and obtained results of erosion resistance tests have been shown and discussed.

\section{Experimental work}

\section{Materials and methods}

For the research purposes composite based on $\mathrm{Al}$ alloy (AlSi7Mg0.3) reinforced with $4 \%$ of FA has been cast using the compo-casting method [20, 21]. The chemical composition of the alloy has been listed in Table 1. This alloy, by its classification and properties, is meant to be used for casting, but during testing, it has also shown itself to be suitable for ECAP.

The FA originates from the Thermal power plant Kolubara, Serbia. FA phase composition has been determined by the X-ray diffraction analysis - XRD. It has shown that the FA belongs to class $\mathrm{F}$, and its composition is dominated by oxides: $\mathrm{Al}_{2} \mathrm{O}_{3}, \mathrm{SiO}_{2}$, $\mathrm{Fe}_{2} \mathrm{O}_{3}$, and others $[7,8]$. 
Table 1. Chemical composition of the AlSi7Mg0.3 alloy

\begin{tabular}{llllllllll}
\hline Chemical element Al & $\mathrm{Si}$ & $\mathrm{Fe}$ & $\mathrm{Cu}$ & $\mathrm{Mn}$ & $\mathrm{Mg}$ & $\mathrm{Zn}$ & $\mathrm{Ti}$ & $\mathrm{Sr}$ \\
\hline Fraction, wt\% & matrix & 7.0 & 0.11 & $<0.01$ & $<0.01$ & 0.37 & 0.01 & 0.12 & 0.056 \\
\hline
\end{tabular}

Equal-channel angular pressing (ECAP)

From the casted ingot, samples with dimensions 12 × 12 x $120 \mathrm{~mm}$ have been cut and subjected to ECAP in the squared section tool, shown in Figure 1.

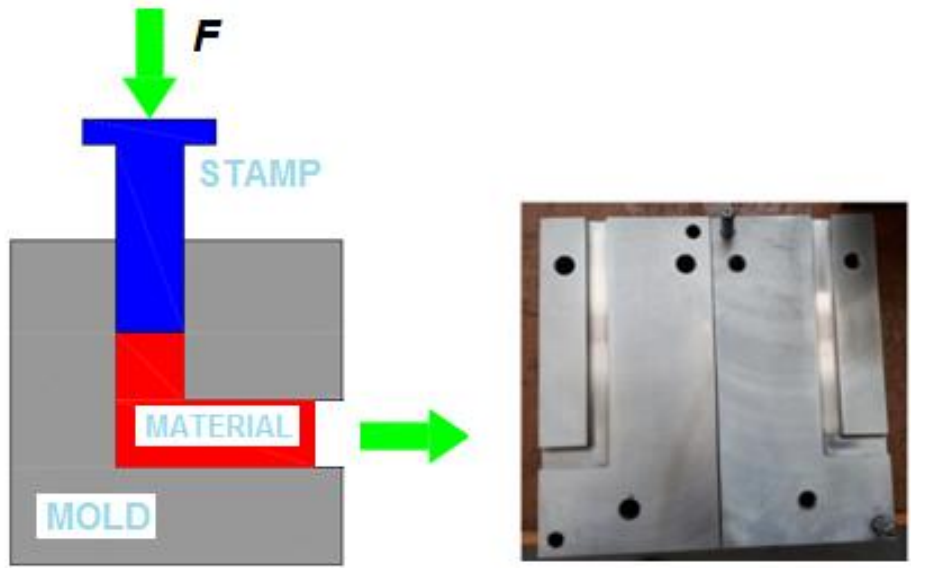

Fig. 1. ECAP tool, on the left-process scheme, on the right-used tool.

Samples have been subjected to multiple passes of ECAP with rotation around the vertical axis for the angle of $90^{\circ}$ after each pass. According to the literature [11, 12], this route, $\mathrm{Bc}$, showed the best results for the improvement of the material properties by ECAP. Samples have been pressed on the hydraulic press "HYDRAUMA" with the rated force of $40 \mathrm{kN}$, velocity below $0.2 \mathrm{~m} / \mathrm{s}$, and constant pressure. To reduce friction, molybdenum-disulfide was used as a lubricant.

\section{Erosion test}

Sample surfaces exposed to solid particle erosion of silicon carbide have been previously ground and polished. The equipment used for the erosion test is shown in Figure 2. The stream of solid particles falls freely while being encountered by samples that rotate at a velocity of 1440 revolutions per minute. The tested surface of each sample has been subjected to erosion for 13 minutes and 53 seconds, which equals a number of 20000 impacts. During the test, the impact angle of particles to the sample surface has varied: $90^{\circ}$ and $30^{\circ}$. The dominant wear mechanism is influenced by the change of the impact angle. At a $90^{\circ}$ angle the dominant wear mechanism is surface fatigue, while at a $30^{\circ}$ angle the dominant wear mechanism is abrasion [14]. 


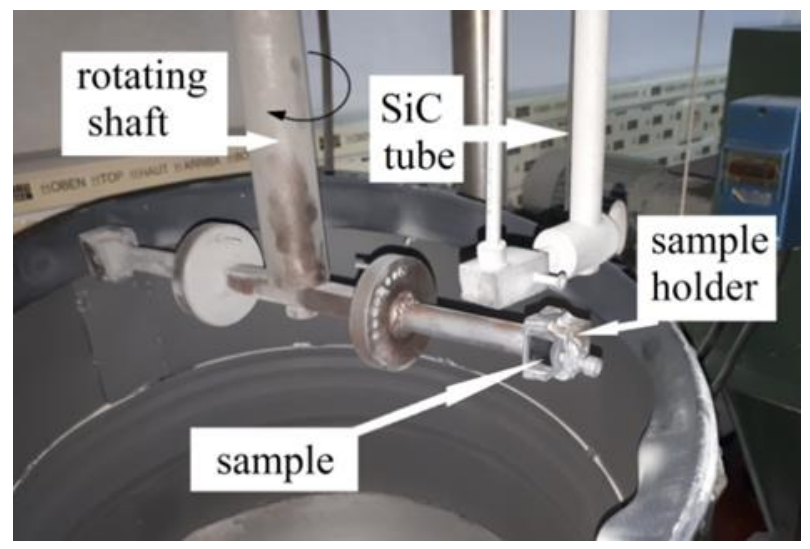

Fig. 2. The equipment used for erosion test.

Images of the microstructure have been recorded with the light microscope Olympus GX51F-5 with a magnification of 100×. Samples of composite with different impact angles and different deformation degrees have been subjected to scanning electron microscope - SEM analysis. The morphology of FA particles was analyzed by SEM JEOL $5800 \mathrm{LV}$.

\section{Results and discussion}

Figure 3. shows the morphology of FA used at composite casting. The spherical shapes that are characteristic of FA are visible in these images. Before usage, FA has been sieved, and particles whose diameter is smaller than 45 microns have been used to reinforce the composite. Some FA analyses are listed in the previously published paper [7], and detailed analyses of the FA from Serbia can be found in the literature [22-24].
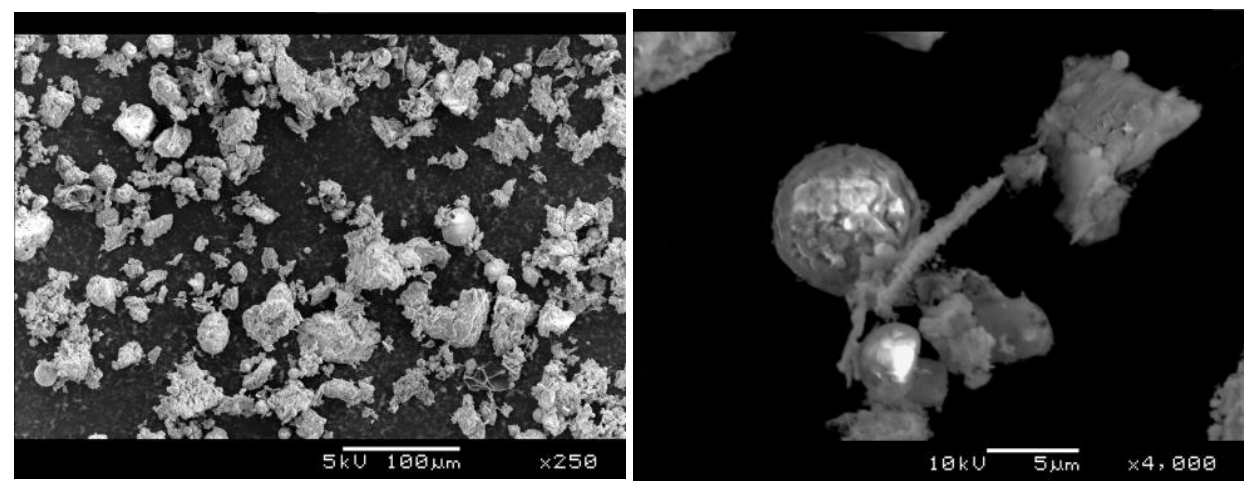

Fig. 3. SEM images of FA particles.

The structure of casted and pressed samples of the AlSi7Mg0.3 alloy and AlSi7Mg0.3 based composite with $4 \%$ of FA is shown in Figure 4. Dendritic structure, common for casted alloys, is observed in Figure 4 where lighter areas represent the primary $\alpha-\mathrm{Al}$ phase and darker areas represent the eutectic. The eutectic in Al-Si alloys is a mixture of primary $\alpha-\mathrm{Al}$ phase and needle-like silicon $(\alpha+\mathrm{Si})$. After one ECAP pass 
(Figure 4.a $\mathrm{a}_{1}$ ), several crystal-shaped darker areas were observed. This sample was thus subjected to SEM-EDS analysis which determined that these darker areas belong to areas rich in $\mathrm{Si}$ (Figure 5). Given that $\mathrm{Al}$ is poorly soluble in $\mathrm{Si}$, in Al-Si alloys pure Si appears as the other phase. Therefore, these Si crystals are probably generated during alloy solidification. The observed morphology of the base alloy matches with literature data $[8$, $25]$.
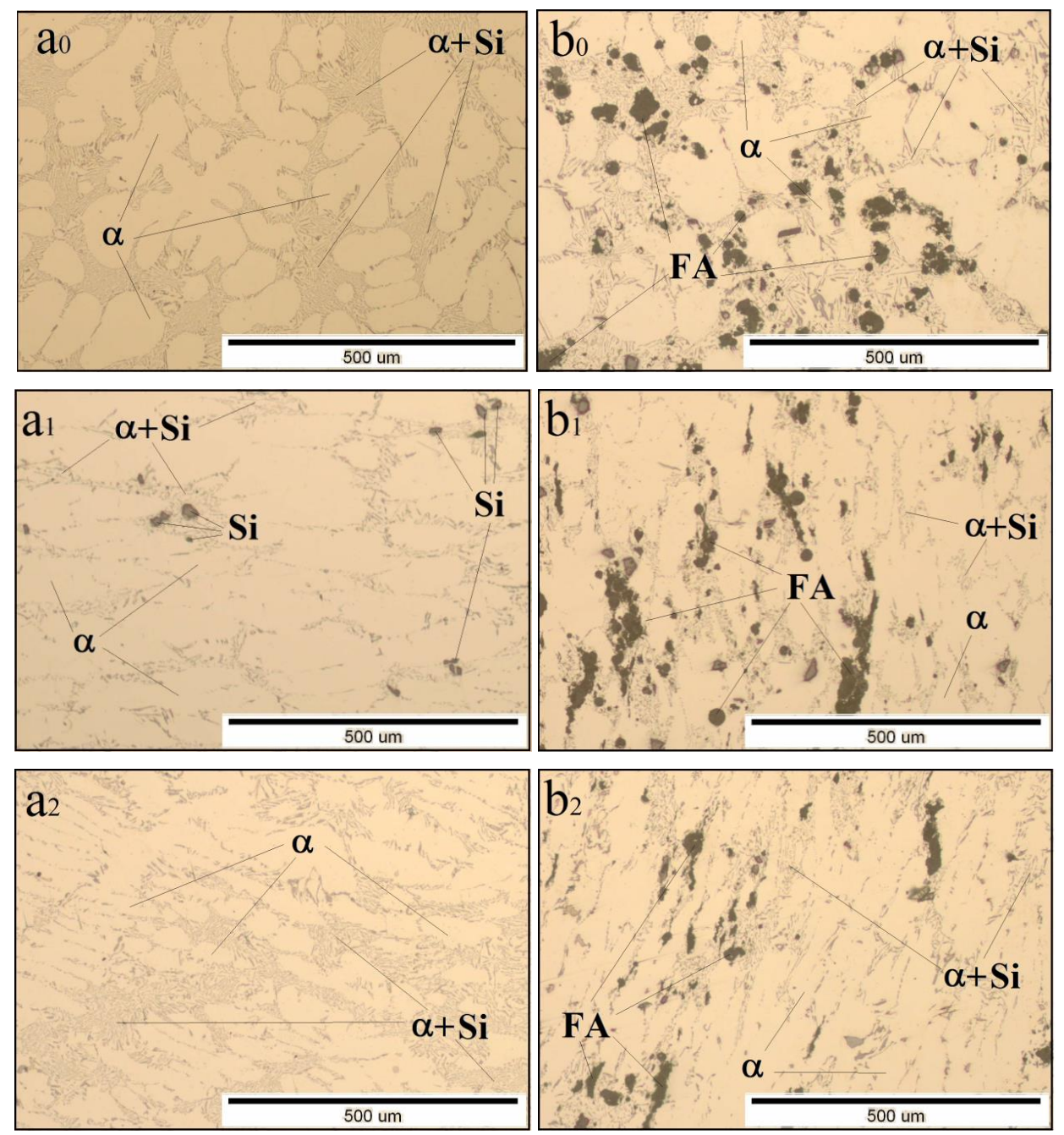

Fig. 4. The microstructure of material: a) AlSi7MgO.3 alloy, b) AlSi7Mg0.3 based composite with $4 \%$ of $F A$. The subscripts represent the number of ECAP passes as zero ECAP passes (0), after one ECAP pass (1), after two ECAP passes (2).

The darker areas of FA agglomerate are visible in the AlSi7Mg0.3 based composite (Figures 4.b). The FA is well bonded to the composite structure, where no fractures, voids or pores have been noticed within the observed section. After each pass of ECAP due to 
the intensive plastic deformation, the dendrite cast structure collapses in both the $\mathrm{AlSi} 7 \mathrm{Mg} 0.3$ alloy and AlSi7Mg0.3 based composite reinforced with 4\% FA. The shape and dimensions of the grains in both materials are changed and the direction of deformation is visible. As every change in the microstructure influences material properties, it is expected that the properties will change regarding the originally casted alloy or composite. Figures 4. $a_{1}$ and 4. $b_{1}$ show samples after one ECAP pass and Figures 4. $\mathrm{a}_{2}$ and 4. $\mathrm{b}_{2}$ show samples after two ECAP passes. After two consecutive passes the structure becomes more homogeneous and additional grain reduction is observed. Within the AlSi7Mg0.3 based composite, the FA particles are additionally distributed inside the matrix after each pass of ECAP, which is shown in Figures $4 . b_{1}$ and $4 . b_{2}$.
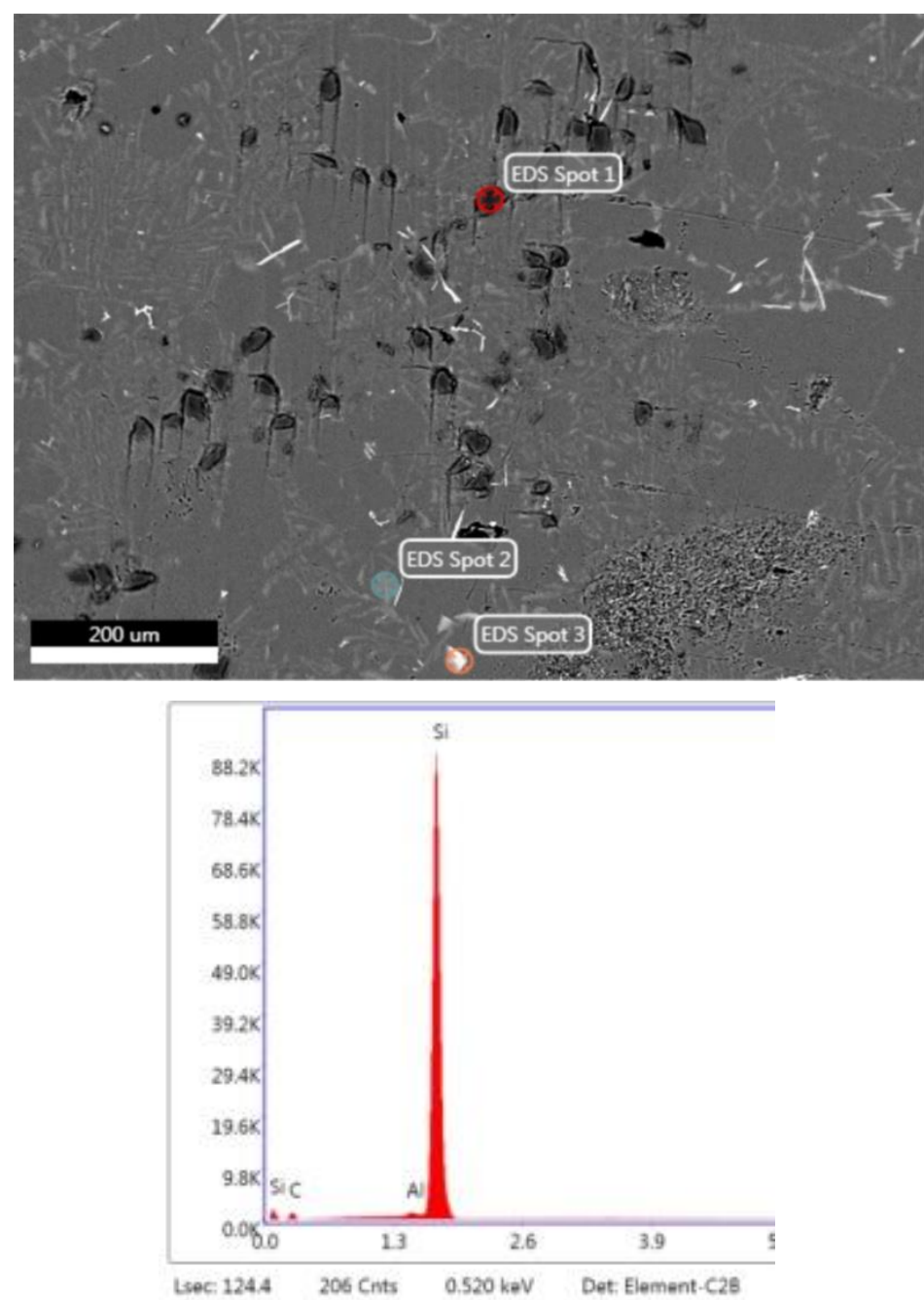

Fig. 5. SEM-EDS analysis of the AlSi7Mg0.3 alloy after one ECAP pass. 
To assess the materials' erosion wear, the mass of the samples was measured on an analytical balance before and after the erosion. Due to different density values of the base alloy and composite, sample mass loss $(\Delta m)$ has been calculated as volume loss $(\Delta V)$ by the expression:

$\Delta V=\frac{\Delta m}{\rho}$

Where $\rho$-density [8]:

- alloy $\rho_{L}=2.67 \mathrm{~g} / \mathrm{cm}^{3}$,

- fly ash

- composite $\rho_{F A}=2.103 \mathrm{~g} / \mathrm{cm}^{3}$, $\rho_{K}=2.64 \mathrm{~g} / \mathrm{cm}^{3}$.

The density of the composite is calculated by the inverse rule of the mixing:

$\frac{1}{\rho_{K}}=\frac{W_{L}}{\rho_{L}}+\frac{W_{F A}}{\rho_{F A}}$

where:

$W_{L}=0.96$ - mass fraction of alloy,

$W_{F A}=0.04$ - mass fraction of FA.

Obtained results of the erosion test on the AlSi7Mg0.3 alloy and AlSi7Mg0.3 based composite reinforced with $4 \% \mathrm{FA}$ are shown in Table 2 and Figure 6. It can be noticed that within the same test parameters wear of the AlSi7Mg0.3 based composite reinforced with $4 \% \mathrm{FA}$ is greater than that of the AlSi7Mg0.3 alloy. Mass and volume loss at most of the samples was greater with the impact angle of the erodent at $30^{\circ}$ than at $90^{\circ}$. Accordingly, it can be concluded that the dominant wear mechanism is the one where abrasion occurrences prevail. However, the AlSi7Mg0.3 based composite reinforced with $4 \%$ FA shows greater wear losses at an impact angle of $90^{\circ}$.

Table 2. The erosion test results of the AlSi7MgO.3 alloy (a) and the AlSi7MgO.3 based composite reinforced with $4 \% \mathrm{FA}(b)$.

\begin{tabular}{lllllll}
\hline Sample & \multicolumn{3}{c}{$\Delta m[\mathrm{mg}]$} & \multicolumn{2}{c}{$\Delta V\left[* 10^{-3} \mathrm{~cm}^{3}\right]$} \\
& & FA [\%] & $90^{\circ}$ & $30^{\circ}$ & $90^{\circ}$ & $30^{\circ}$ \\
\hline \multirow{2}{*}{ 0 ECAP passes } & $\mathrm{a}_{0}$ & 0 & 0.50 & 1.43 & 0.19 & 0.54 \\
& $\mathrm{~b}_{0}$ & 4 & 0.80 & 2.83 & 0.30 & 1.07 \\
\hline \multirow{2}{*}{ 1 ECAP pass } & $\mathrm{a}_{1}$ & 0 & 0.83 & 1.17 & 0.31 & 0.44 \\
& $\mathrm{~b}_{1}$ & 4 & 3.83 & 3.03 & 1.45 & 1.15 \\
\hline \multirow{2}{*}{ 2 ECAP passes } & $\mathrm{a}_{2}$ & 0 & 0.27 & 0.83 & 0.10 & 0.31 \\
& $\mathrm{~b}_{2}$ & 4 & 0.97 & 1.10 & 0.37 & 0.42 \\
\hline
\end{tabular}


According to Figure 6, the greatest solid particle erosion resistance is shown in samples of the AlSi7Mg0.3 alloy (labeled as an alloy) after two ECAP passes compared to AlSi7Mg0.3 based composite reinforced with 4\% FA (labeled as composite). Figure 6.a) illustrates results for the erosion impact angle of $90^{\circ}$, where it can be noticed that samples of both materials after one ECAP pass, show greater wear than the cast and twice deformed material.

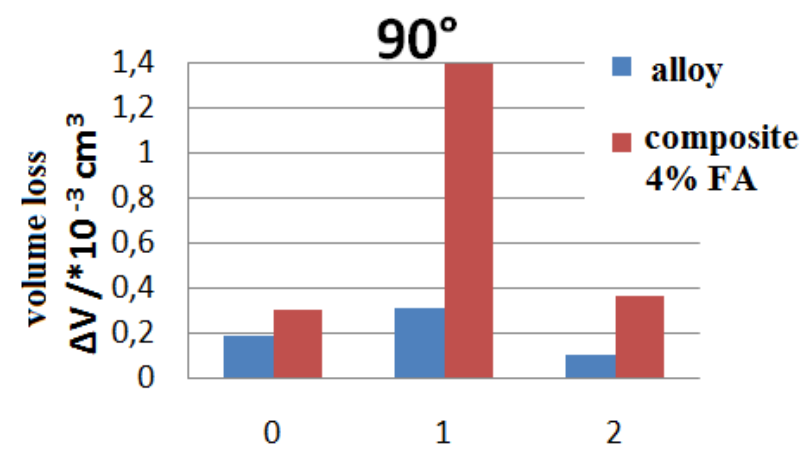

a)

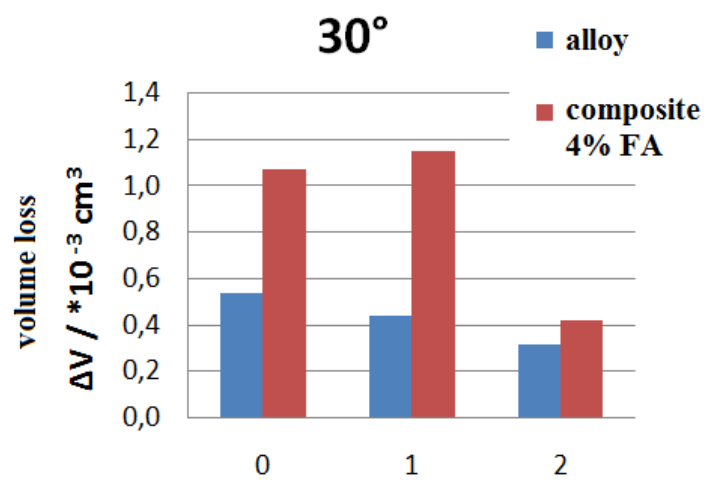

b)

Fig. 6. Volume loss relative to the number of ECAP passes for the impact angle of a) $90^{\circ}$ and $b$ ) $30^{\circ}$. Samples of the AlSi7MgO.3 alloy are labeled as alloy while the samples of AlSi7Mg0.3 based composite reinforced with $4 \%$ FA are labeled as composite.

Erosion wear of the AlSi7Mg0.3 alloy at an impact angle of $30^{\circ}$ is reduced after each ECAP pass, as shown in Figure 6.b). It can be noticed that the resistance of the AlSi7Mg0.3 based composite reinforced with $4 \%$ FA is increased after two ECAP passes. For a better understanding of the gained results samples have been subjected to SEM analysis.

The eroded surface of the sample after one ECAP pass and after being submitted to the erosion test with the impact angle of $90^{\circ}$ is shown in Figure 7, where the greatest material loss has been measured. 


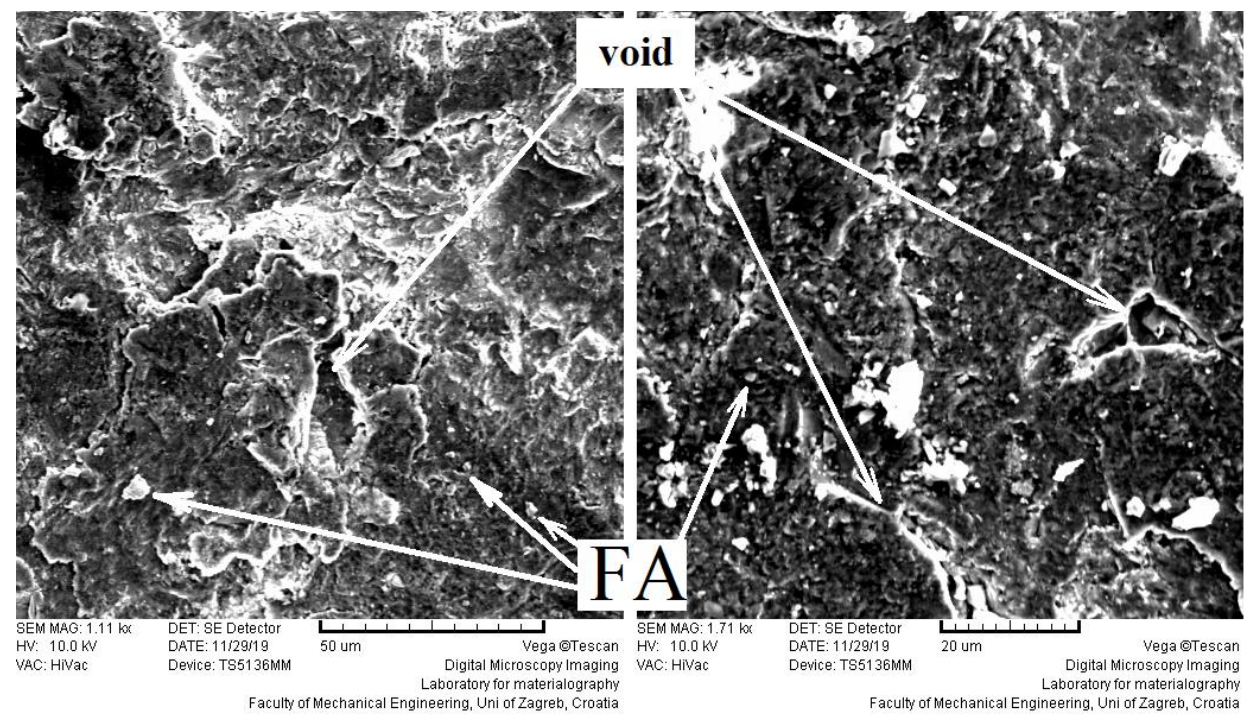

Fig. 7. The surface of the AlSi7MgO.3 based composite reinforced with $4 \%$ FA after one ECAP pass and erosion test at $90^{\circ}$ impact angle.

Figure 7. shows particles of FA that are well incorporated into the AlSi7Mg0.3 matrix, however, surface irregularities are observed as well. Some voids, that apparently originate by the "falling out" of smaller particles of FA and/or matrix particles, can be seen. Considering that erosion wear at a $90^{\circ}$ angle was also increased in the alloy after one ECAP pass, it can be concluded that bonds between crystal grains have been weakened due to intensive plastic deformation. Passing through the ECAP channel the material changes direction flow and plastic deformation shear forces are severe. In the shear planes, microfractures may occur as well as residual stress, which weakens the bonds inside the crystal structure. Due to the large impact angle of the eroding particles, the dominant wear mechanism is surface fatigue which at the end leads to the fallout of the weakened particles from their place. The same sample of composite shows smaller erosion wear at a $30^{\circ}$ angle than at a $90^{\circ}$ where the fine FA particles were resisting the abrasive impact of $\mathrm{SiC}$.

Figure 8. shows the surface of the AlSi7Mg0.3 based composite reinforced with $4 \%$ FA after 2 ECAP passes eroded at a $30^{\circ}$ impact angle. After the second ECAP pass, the observed composite structure is more homogenous with a fine distribution of FA particles and with less expressed surface inequalities compared to Figure 7 . When rotating the material around the vertical axis before the second ECAP pass a change of the shear planes occurs and the microstructure becomes finer and more compact. Cracks disappear and the material shows better erosion resistance. 


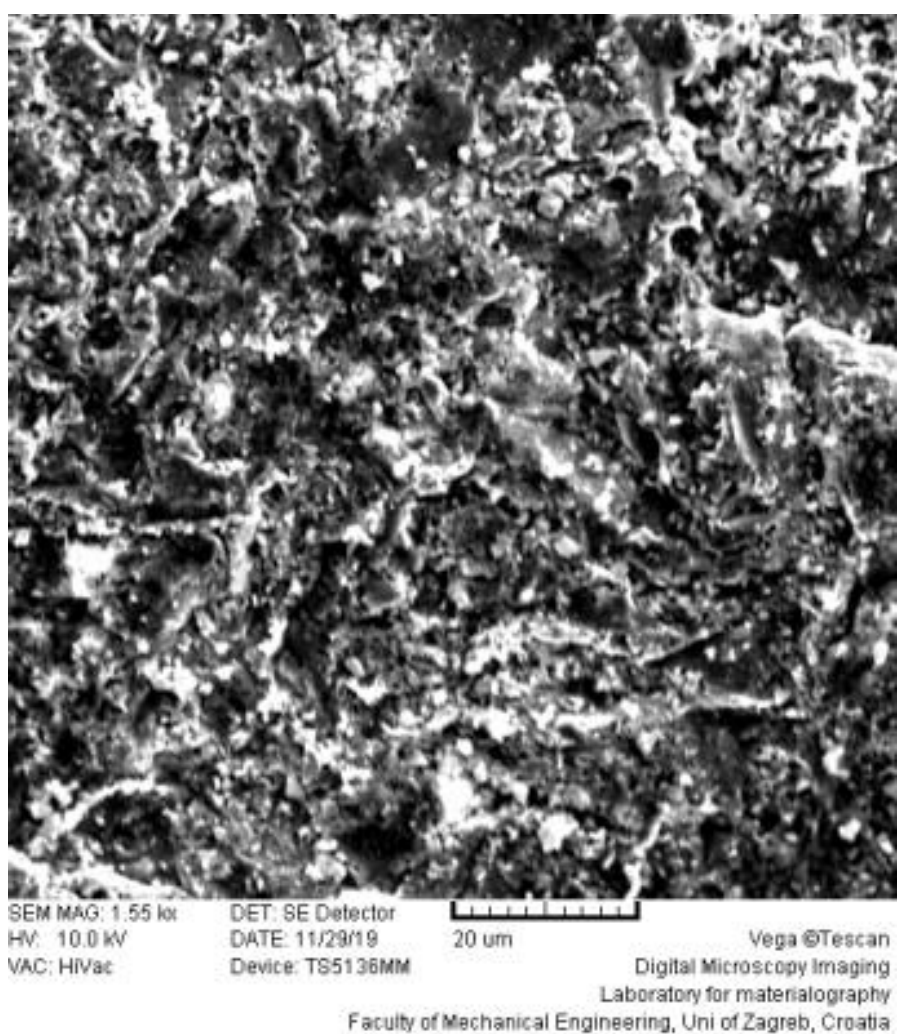

Fig. 8. The surface of the AlSi7MgO.3 based composite reinforced with $4 \%$ FA after the second ECAP pass and erosion test at a $30^{\circ}$ impact angle.

\section{Conclusions}

Based on the conducted experimental research the following can be concluded:

- the composite material based on AlSi7Mg0.3 alloy with FA as the reinforcement, that is suitable for ECAP can be produced by compo-casting,

- multiple ECAP passes can improve the microstructure and the solid particle erosion resistance of the examined materials,

- the tested materials generally show higher wear resistance at a $90^{\circ}$ angle where material fatigue predominates, than at a $30^{\circ}$ angle where abrasion-related phenomena predominate,

- the exception was an AlSi7Mg0.3 based composite reinforced with 4\% FA material in which the erosion wear at $30^{\circ}$ angle was less than at $90^{\circ}$ angle after one ECAP pass, 
- the SEM analysis showed changes in the microstructure corresponding to the "falling out" of particles from the observed composite sample's surface subjected to one ECAP pass, after two passes of ECAP, SEM analysis showed an improvement in the structure of the AlSi7Mg0.3 based composite reinforced with $4 \%$ FA, where FA particles are well integrated into the matrix, and further investigation of the described composite to replace the base alloy is justified.

\section{Acknowledgment}

The authors would like to express their sincere gratitude to dr Ilija Bobic for casting samples, and providing irreplaceable support during the entire research.

\section{References}

[1] A. Dwivedi, M.K. Jain: Recent Res Sci Technol, 6(1) (2014) 30-35.

[2] R. Kurda, J.D. Silvestre, J.de Brito: Heliyon, 4(4) (2018) e00611.

[3] J. Hanania, A. Sheardown, K. Stenhouse, J. Donev: "Energy Education - Fly ash", https://energyeducation.ca/encyclopedia/Fly_ash Accessed: 29 October 2019.

[4] SH. Jaiswal, M. Das, S. K. Maiti: Indian J Environ Prot, 26 (2006) 268-275.

[5] R.K. Roomey, E. Haque, S. Akhter: American Journal of Engineering Research, 6(12) (2017) 334-339.

[6] S.H. Juang, LJ. Fan, H.P.O. Yang: Int J Precis Eng Manuf, 16(7) (2015) 13211327.

[7] M. Muslić, V. Maksimović, I. Bobić: In: Proceedings book $17^{\text {th }}$ IFC. Eds.: N. Dolić, Z. Zovko Brodarec, A. Begić Hadžipašić, University of Zagreb, Faculty of Metallurgy, Sisak, Croatia 2018, $364-371$.

[8] V. Maksimović, A. Devečerski, A. Došen, I. Bobić, M. Erić, T. Volkov-Husović: T Indian I Metals, 70(1) (2017) 97-105.

[9] S. Selvi, E. Rajasekar: J Mech Sci Technol, 29(2) (2015) 785-792.

[10] D. Mohana Rao, M.E. Bapi Raju Bandam: International Journal of Innovative Science and Modern Engineering, 3(1) (2014) 1-5.

[11] A. Bhandakkar, K. Singh, P.K. Limaye, Sh.M.L. Sastry: International Journal of Trend in Research and Development, 3(6) (2016) 688-695.

[12] F. Djavanroodi, B. Omranpour, M. Ebrahimi, M. Sedighi: Prog Nat Sci: Mater Int, 22(5) (2012) 452-460.

[13] G.N. Lokesh, M. Ramachandra, K.V. Mahendra: Int J Compos Mater, 4(1) (2014) 21-29.

[14] V. Rede, K. Grilec: Strojarstvo, 51(6) (2009) 613-621.

[15] I. Kleis, P.Kulu: Solid Particle Erosion: Occurrence, Prediction and Control, first ed., Springer-Verlag London Limited, London, UK, 2008.

[16] J.R. Laguna-Camacho, M. Vite-Torres, E.A. Gallardo-Hernández and E.E. VeraCárdenas: Tribology in Engineering Chapter 5, first ed., InTech, Rijeka, Croatia, 2013, 63-78.

[17] A.P. Harsha, D. K. Bhaskar: Mater Des, 29 (2008) 1745-1754.

[18] S.R. More, D.V. Bhatt, J.V. Menghani: T Indian I Metals, 72(12) (2019) 31913199.

[19] J. Malik, I.H. Toor, W.H. Ahmed, Z.M. Gasem, M.A. Habib, R. Ben-Mansour, H.M. Badr: J Mater Eng Perform, 23(6) (2014) 2274-2282.

[20] M. Babic, S. Mitrovic, D. Džunić, B. Jeremic, I. Bobić: Tribol Lett, 37(2) (2010) 401-410. 
[21] A. Vencl, I. Bobić, M.T. Jovanović, M. Babić, S.Mitrović: Tribol Lett, 32 (2) (2008) 159-170.

[22] V. Nikolić, M. Komljenović, Z. Baščarević, N. Marjanović, Z. Miladinović, R. Petrović: Constr Build Mater, 94 (2015) 361-370.

[23] N. Marjanović, M. Komljenović, Z. Baščarević, V. Nikolić, R. Petrović: Ceram Int, 41 (2015) 1421-1435.

[24] N. Marjanović, M. Komljenović, Z. Baščarević, V. Nikolić: Constr Build Mater, 57 (2014) 161-142.

[25] H. Baker: Alloy Phase Diagrams, ASM Handbook Vol. 3. first ed., ASM International, Materials Park, Ohio, USA, 1992.

\section{(c) (i) Creative Commons License}

This work is licensed under a Creative Commons Attribution 4.0 International License. 